\title{
Assessment of Carotid Artery Intima-Media Thickness and Lipid Profile in Term Neonates Born to Smoking Mothers
}

\author{
Hande Turan ${ }^{1,{ }^{*}}$, Timur Meșe ${ }^{2}$, Onder Doksoz ${ }^{2}$ and Volkan Turan ${ }^{3}$ \\ ${ }^{1}$ Cerrahpasa University School of Medicine, Istanbul, Turkey \\ ${ }^{2}$ Department of Pediatric Cardiology, Behcet Uz Children Hospital, Izmir, Turkey \\ ${ }^{3}$ Istanbul Health and Technology University School of Medicine, Istanbul, Turkey \\ "Corresponding author: Cerrahpasa University School of Medicine, Istanbul, Turkey. Email: dr.handeerdogan@gmail.com
}

Received 2020 December 20; Revised 2021 September 29; Accepted 2021 October 25.

\begin{abstract}
Background: It is well-known that cigarette smoke contains chemical substances, including nicotine and carbon monoxide, which can have harmful effects on cardiovascular function.

Objectives: This study aimed to investigate and compare lipid levels and carotid artery intima-media thickness (CAIMT) among neonates born to smoking and nonsmoking mothers.

Methods: This study was conducted on 40 term neonates (over 37 weeks of gestation) within the age range of 0 - 30 days born to smoking mothers (study group) and 34 term neonates born to nonsmoking mothers (control group). Both groups were assessed prospectively for triglyceride (TG), total cholesterol (TC), low-density lipoprotein cholesterol (LDL-C), high-density lipoprotein cholesterol (HDL-C), and CAIMT.

Results: There was no difference in the mean age of mothers between control and study groups (29.0 \pm 4.5 vs. $29.3 \pm 5.7$ years; $\mathrm{P}=0.31$. The CAIMT was observed as similar between the groups ( $0.35 \pm 0.05 \mathrm{vs}$. $0.36 \pm 0.05 \mathrm{~mm}$ in control and study groups, respectively; $\mathrm{P}=0.665$ ). Although HDL-C levels were significantly lower in the study group (48.5 $\pm 16.2 \mathrm{vs.} 39.1 \pm 17.8 \mathrm{mg} / \mathrm{dL} ; \mathrm{P}=$ 0.021), no difference was observed in LDL-C, TC, and TG levels between the two groups.

Conclusions: Based on the results, there were no differences in CAIMT and lipid profile other than low HDL levels between term neonates born to smoking mothers and neonates born to nonsmoking mothers. Atherosclerosis is a disease in which numerous factors play a role in the formation beginning in the fetal period and emerging with clinical findings in advanced age; therefore, it is required to perform further studies with longer follow-up and larger sample size to confirm the present study findings.
\end{abstract}

Keywords: Atherosclerosis, Carotis Artery Intima-Media Thickness, Gestational Tobacco Exposure, Lipid Profile

\section{Background}

Smoking is defined as a biopsychosocial state of intoxication by the World Health Organization (WHO) (1). Smoking is a very common habit in society, and $90 \%$ of smokers begin this habit before the age of 20 years. Since the number of female smokers is being increased, smoking is more frequently encountered during pregnancy (2). This is a major public health problem because smoking is not only harmful to woman's health, but it also might lead to gestational complications, such as preterm birth, low birth weight, and serious health problems in newborns and early childhood.

Atherosclerosis is the most common cause of mortality in developed countries. It might lead to several diseases, including cerebrovascular disease, coronary heart disease, and peripheral arterial occlusion, causing severe mortality and morbidity. The WHO reported atherosclero- sis would be the first common cause of mortality worldwide in the near future (3). Studies for the early detection of atherosclerotic lesions showed that the measurement of intima-media thickness in the carotid arteries and abdominal aortic artery is reliable and helpful and has been shown to be an early marker of endothelial organ damage and initial finding of atherosclerotic heart disease (ASHD) $(4,5)$.

Atherosclerosis is known to be associated with serum lipid and lipoprotein concentrations. Epidemiological studies report that ASHD is positively correlated with total cholesterol (TC) and low-density lipoprotein cholesterol (LDL-C) and negatively correlated with high-density lipoprotein cholesterol (HDL-C) (6-10). Gestational exposure to smoking has been demonstrated to affect serum lipid levels in various ways; however, studies investigating the effect of gestational smoking on atherosclerotic markers in newborns had no consensus of opinion due to differ- 
ent findings (11-13).

\section{Objectives}

The present study aimed to investigate blood lipid levels and carotid artery intima-media thickness (CAIMT) in newborns with exposure to gestational smoking and compare the results with those of age- and gender-matched healthy controls with no smoking exposure.

\section{Methods}

\subsection{Patients}

A total of 74 patients presented to Dr. Behcet Uz Children's Training and Research Hospital, Cardiology Outpatient Clinic, İzmir, Turkey, were prospectively included in the study. After receiving approval from the Ethics Committee (12/12/2013104), the newborns were assigned to two groups according to the smoking status of mothers during pregnancy, namely newborns of smoking mothers $(\mathrm{n}=$ 40 ; study group) and nonsmoking mothers ( $n=34$; control group). All patients signed the informed consent form.

Term newborns aged 0 - 30 days who were born to healthy mothers with no additional diseases were included in the study as controls. Newborns of hypertensivepreeclamptic-eclamptic mothers and diabetic mothers, those with a history of prematurity, familial hypercholesterolemia, familial history of early atherosclerosis, metabolic disease or chronic disease, and passively exposed to tobacco smoke were excluded from the study.

The pack-years of the mothers in the study group were calculated. The pack-year is a unit for measuring the amount an individual has smoked over a long period. It is calculated by multiplying the number of packs of cigarettes smoked per day by the number of years the individual has smoked. Newborns of the mothers who were irregularly smoking were not included in the study to avoid the risk of affecting the study results. Both groups were compared regarding demographic characteristics, blood lipid profile, blood glucose, blood pressure, heart rate, and CAIMT.

\subsection{Measurement of CAIMT}

The carotid arteries are most commonly used in studies due to their superficial localization, easiness of visualization, size, and stillness $(14,15)$. Before initiating ultrasound, newborns were laid in a dark temperaturecontrolled room for 10 - 15 minutes. All carotid artery imaging examinations were performed by a single pediatric cardiologist who was blinded to the clinical and laboratory data of the newborns. Ultrasound examinations were carried out with Vivid S6 (General Electric Healthcare, Milwaukee, WI, USA). The images were acquired using an L12 linear probe. The measurements were made for the newborns lying in supine position with the head slightly brought to extension and turned toward the opposite side of the carotid artery studied. All examinations were performed in accordance with the predetermined standard scanning protocol. The common carotid artery segment was scanned at $1-2 \mathrm{~cm}$ proximal to the carotid bulb. The distal wall was focused during the scanning. The images were digitally recorded, and the digitally stored scans were manually analyzed by a single reviewer who was not aware of the patients' risk factors. The walls distal to the left common carotid artery were measured three times during the analysis, and the average of these results was used (Figure 1).

\subsection{Blood Glucose-Lipid Profile}

The blood samples were collected between 08:00 10:00 am following 4-hour fasting. All blood samples were kept in a $-80^{\circ} \mathrm{C}$ refrigerator until analysis. Blood glucose was determined by the glucose oxidase method and the blood glucose kit in a fully automatic chemistry analyzer. The triglyceride (TG), TC, LDL-C, and HDL-C of serum were measured with TC kit, TG kit, HDL-C kit, and LDL-C kit. All blood samples of newborns were drawn at the age of 15 - 30 days.

\subsection{Blood Pressure and Heart Rate}

Blood pressure was measured while the newborns were awake and calm in a lying position using a cuff appropriate to their age and size of the right arm. Blood pressure was measured three times using a standard mercury sphygmomanometer.

\subsection{Statistics}

Statistical analysis was performed using the Statistical Package for the Social Sciences software (release 15.0; SPSS Inc., Chicago, IL, USA). The variables were investigated using visual (e.g., histograms and probability plots) and analytical (e.g., Kolmogorov Smirnov test/Shapiro-Wilk test) methods to determine whether or not they were normally distributed. The continuous data were analyzed by a Student's $t$-test. The chi-square and Fischer's exact test were used to compare the proportions of different groups. The correlation coefficients and their significances were calculated using the Pearson correlation test. A p-value less than 0.05 was considered statistically significant.

\section{Results}

In the present study, the study group consisted of 40 neonates born to smoking mothers; nevertheless, the control group included 34 neonates born to nonsmoking mothers. No statistically significant difference was observed in the mean age of mothers between the two groups 


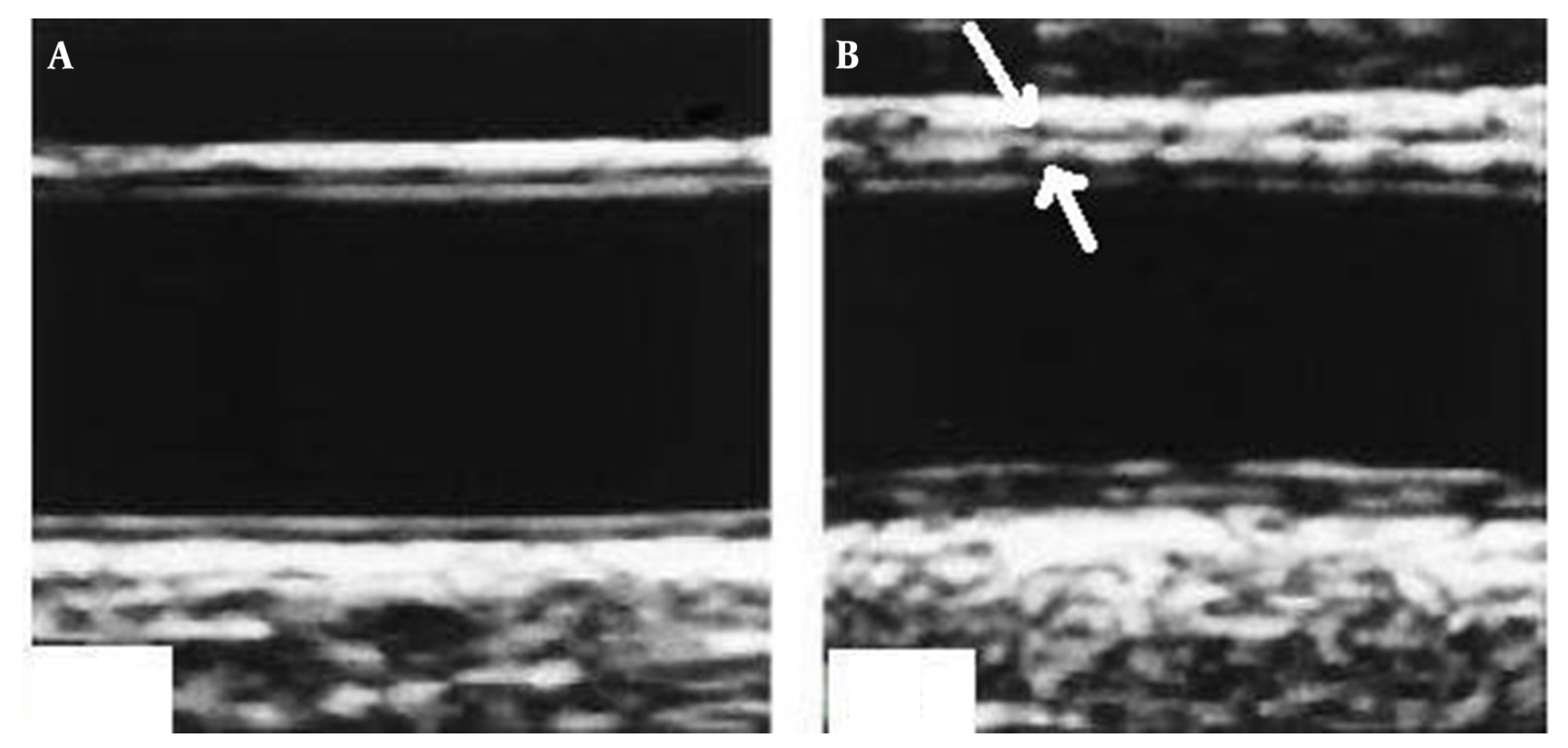

Figure 1. Measurement of carotid artery intima-media thickness; A, normal thickness; B, increased thickness.

(29.0 \pm 4.5 vs. $29.3 \pm 5.7$ years, respectively; $\mathrm{P}=0.316)$. Table 1 shows the demographics of both groups. No statistically significant differences were observed in the gender and nutritional patterns of the newborns. There was no significant difference in the birth weights (3334 \pm 442 vs. $3222 \pm 440$ gr; $\mathrm{P}=0.285$ ) and current weights (3830.9 \pm 520 vs. $3739.0 \pm 740 \mathrm{gr} ; \mathrm{P}=0.546)$ of newborns between the control and study groups (Table 1 ).

There were no statistically significant differences between the control and study group in heart rate, fasting blood glucose, and blood pressure (heart rate: $146.5 \pm 20.1$ vs. $141.0 \pm 14.8$ beats/minute, $\mathrm{P}=0.177$; fasting blood glucose: $86.4 \pm 10.6$ vs. $84.0 \pm 13.7 \mathrm{mg} / \mathrm{dL}, \mathrm{P}=0.412$; blood pressure: systolic: $86.3 \pm 9.1 \mathrm{vs.} 86.6 \pm 9.8 \mathrm{mmHg}, \mathrm{P}=0.906$; diastolic: $52.6 \pm 9$ vs. $51.9 \pm 10.9 \mathrm{mmHg}, \mathrm{P}=0.768)$. No statistically significant differences were noticed between both groups in mean CAIMT and body weight-adjusted CAIMT values, although CAIMT was thicker in the neonates of smoking mothers, compared to that of nonsmokers ( 0.35 \pm 0.05 vs. $0.36 \pm 0.05 \mathrm{~mm}$, respectively; $\mathrm{P}=0.665 ; 0.093$ \pm 0.023 vs. $0.099 \pm 0.0160 \mathrm{~mm} / \mathrm{kg}$, respectively; $\mathrm{P}=0.212$ ) (Table 2). When the control and study groups were compared for blood lipid levels, the study groups had higher LDL-C, TC, and TG levels, although the differences did not reach a statistical significance (LDL-C: $40.7 \pm 17.4$ vs. 45.8 $\pm 28.0 \mathrm{mg} / \mathrm{dL}, \mathrm{P}=0.356$; TC: $109.0 \pm 24.4$ vs. $113.8 \pm 30.0$ $\mathrm{mg} / \mathrm{dL}, \mathrm{P}=0.459 ; \mathrm{TG}: 127.7 \pm 35.6$ vs. $138.7 \pm 42.7 \mathrm{mg} / \mathrm{dL} ; \mathrm{P}=$ $0.286)$. On the other hand, the control group showed a significantly higher HDL-C level than the study group (48.5 \pm 16.2 vs. $39.1 \pm 17.8 \mathrm{mg} / \mathrm{dL} ; \mathrm{P}=0.021$ ) (Table 2 ).
There was a statistically significant negative correlation between CAIMT and HDL-C $(\mathrm{r}=-0.245 ; \mathrm{P}=0.035)$. The CAIMT was not significantly correlated with the levels of LDL-C ( $\mathrm{r}=0.228 ; \mathrm{P}=0.051)$, TC $(\mathrm{r}=0.035 ; \mathrm{P}=0.776)$, and TG $(r=0.186 ; P=0.112)$. No significant difference was observed when the groups were compared for atherogenic index parameters (i.e., LDL-C/HDL-C and TC/HDL-C) (Table 2). The HDL-C levels measured in the newborns showed a statistically significant negative correlation with the packyear values of the mothers $(r=-0.266 ; P=0.023)$.

\section{Discussion}

This study investigated and compared the lipid levels and CAIMT among neonates born to smoking and nonsmoking mothers. The obtained results showed that mean HDL-C levels were lower in term neonates born to smoking mothers, although mean CAIMT values were similar between the groups. To the best of our knowledge, this has been the first study with the youngest population who were exposed to maternal smoking in utero, and the findings showed for the first time that HDL-C levels seem to be influenced by smoking as early as in the utero period, compared to other parameters related to atherosclerosis.

Numerous studies have shown an inverse association between cigarette smoking and HDL-C. In addition to cigarette smoking's impact on HDL metabolism via altering cholesteryl ester transfer protein and the critical enzymes of lipid transport, HDL is susceptible to oxidative modifications, making HDL dysfunctional later in life (16). 
Turan $\mathrm{Het}$ al.

\begin{tabular}{|c|c|c|c|}
\hline Variables & $\operatorname{Control~Group~}(\mathbf{n}=\mathbf{3 4})$ & Study Group $(n=40)$ & P-Value \\
\hline \multicolumn{4}{|c|}{ Mothers } \\
\hline Age $(y)$ & $29.0 \pm 4.5$ & $29.3 \pm 5.7$ & 0.316 \\
\hline Educational level & & & 0.009 \\
\hline Primary & $11(32.3)$ & $24(60)$ & \\
\hline Secondary & $10(29.4)$ & $11(27.5)$ & \\
\hline Tertiary & $13(38.2)$ & $5(12.5)$ & \\
\hline Employment status & & & 0.215 \\
\hline Employed & $14(41.1)$ & $11(27.5)$ & \\
\hline Unemployed & $20(58.9)$ & $29(72.5)$ & \\
\hline \multicolumn{4}{|c|}{ Newborns } \\
\hline Age (day) & $16.7 \pm 9.0$ & $17.4 \pm 8.7$ & 0.743 \\
\hline Gender & & & 0.771 \\
\hline Male & $19(55.8)$ & $21(52.5)$ & \\
\hline Female & $15(44.2)$ & $19(47.5)$ & \\
\hline Birth weight (g) & $3334 \pm 442$ & $3222 \pm 440$ & 0.285 \\
\hline Current weight (g) & $3830.9 \pm 520$ & $3739.0 \pm 740$ & 0.546 \\
\hline \multicolumn{4}{|l|}{ Feeding type } \\
\hline Breast milk & $21(61.7)$ & $23(57.5)$ & 0.163 \\
\hline Formula & $0(0)$ & $4(10.0)$ & 0.076 \\
\hline Breast milk + formula & $13(38.3)$ & $13(32.5)$ & 0.947 \\
\hline
\end{tabular}

${ }^{a}$ Values are expressed as No. (\%) or mean \pm standard deviation.

${ }^{\mathrm{b}} \mathrm{P}$-value $<0.05$ was considered statistically significant.

Table 2. Comparison of Blood Lipid Profile, Blood Glucose, Blood Pressure, Heart Rate, and Carotid Artery Intima-Media Thickness Between Two Groups a, b

\begin{tabular}{|c|c|c|c|}
\hline Variables & Control Group $(n=34)$ & Study Group $(n=40)$ & P-Value \\
\hline Heart rate (beats/min) & $146.5 \pm 20.1$ & $141.0 \pm 14.8$ & 0.177 \\
\hline Fasting blood glucose (mg/dL) & $86.4 \pm 10.6$ & $84.0 \pm 13.7$ & 0.412 \\
\hline \multicolumn{4}{|l|}{ Blood pressure (mmHg) } \\
\hline SBP & $86.3 \pm 9.1$ & $86.6 \pm 11.8$ & 0.906 \\
\hline DBP & $52.6 \pm 9.0$ & $51.9 \pm 10.9$ & 0.768 \\
\hline CAIMT (mm) & $0.35 \pm 0.05$ & $0.36 \pm 0.05$ & 0.665 \\
\hline CAIMT/Body weight $(\mathrm{mm} / \mathbf{k g})$ & $0.093 \pm 0.023$ & $0.099 \pm 0.0160$ & 0.212 \\
\hline TG $(\mathbf{m g} / \mathrm{dL})$ & $128.7 \pm 35.6$ & $138.7 \pm 42.7$ & 0.286 \\
\hline $\mathrm{TC}(\mathrm{mg} / \mathrm{dL})$ & $109.0 \pm 24.4$ & $113.8 \pm 30.0$ & 0.459 \\
\hline LDL-C (mg/dL) & $40.7 \pm 17.4$ & $45.8 \pm 28.0$ & 0.356 \\
\hline HDL-C (mg/dL) & $48.5 \pm 16.2$ & $39.1 \pm 17.8$ & 0.021 \\
\hline LDL-C/HDL-C & $1.37 \pm 0.63$ & $1.71 \pm 2.51$ & 0.457 \\
\hline TC/HDL-C & $3.47 \pm 1.75$ & $4.32 \pm 4.62$ & 0.334 \\
\hline
\end{tabular}

Abbreviations: CAIMT, carotid artery intima-media thickness; DBP, diastolic blood pressure; HDL-C, high-density lipoprotein-cholesterol; LDL-C, low-density lipoproteincholesterol; SBP, systolic blood pressure; TC, total cholesterol; TG, triglyceride

${ }^{a}$ Values are expressed as No. (\%) or mean \pm standard deviation.

${ }^{\mathrm{b}}$ P-value $<0.05$ was considered statistically significant. 
Although exposure to smoking has been demonstrated to affect serum lipid levels and CAIMT in neonates, this study showed that smoking might alter lipid profile even in utero.

Animal and human studies investigating the effect of gestational exposure to smoking or nicotine on newborns from the aspect of atherosclerotic findings have obtained different findings $(17,18)$. In a study performed by Gunes et al. (11), it was shown that nicotine exposure during intrauterine life and lactation period increases aortic intimamedia thickness in a dose-dependent manner in offsprings of rats. In a series of 732 cases, including smoking and nonsmoking mothers by Geerts et al. (12), the CAIMT of the neonates born to these mothers measured after adjusting several risk factors, such as age, gender, body mass index, blood pressure, LDL-C, HDL-C, and CAIMT, was shown significantly higher in the newborns of smoking mothers. In a prospective population-based study, Geerts et al. (13) evaluated the CAIMT of 259 children at 1 month and 5 years of age according to the smoking status of their mothers during and after pregnancy. Although no significant difference was observed, there was a 23.3-micrometer increase in the intima-media thickness of the neonates born to the mothers who smoked both during and after pregnancy. In the present study, although CAIMT and body weight-adjusted CAIMT values were observed to be higher in the neonates of smoking mothers, compared to those of nonsmokers, it was impossible to find a statistically significant difference in CAIMT between the two groups.

Ayer et al. (19) evaluated children born to mothers who were smoking during pregnancy when they were aged 8 years in terms of blood lipid and blood pressure levels. The aforementioned study initially included 616 newborns aged over 36 weeks of gestation and weighed over 2500 gr; however, blood lipid levels, blood pressure, and CAIMT could be obtained in 405 patients when they were 8 years. The results of the aforementioned study showed that children born to smoking mothers had lower HDL-C (1.32 vs. $1.50 \mathrm{mmol} / \mathrm{L} ; 95 \%$ confidence interval (CI): -0.28 to -0.08 ; $\mathrm{P}=0.0005)$, higher TG (1.36 vs. $1.20 \mathrm{mmol} / \mathrm{L} ; 95 \% \mathrm{CI}: 1.01$ - 1.30; $\mathrm{P}=0.04)$, and higher systolic blood pressure (102.1 vs. $99.9 \mathrm{mmHg}$; 95\% CI: 0.6 - 3.8; $\mathrm{P}=0.006$ ) levels; nevertheless, no significant difference was observed in CAIMT between the children of mothers who were smoking and nonsmoking during pregnancy ( 0.59 and $0.60 \mathrm{~mm}$; $\mathrm{P}=$ 0.31). Through adjustment according to other risk factors, the aforementioned study reported that HDL-C level was lower by $0.14 \mathrm{mmol} / \mathrm{L}$ in children born to smoking mothers. Although the relationship between a decrease in HDL$\mathrm{C}$ at such level and incidence of atherosclerosis in children is unclear, population studies conducted in adults indicated that after adjusting the other risk factors, even minor alterations in HDL-C might lead to significant changes in the prevalence of coronary heart disease (20).

In a similar study with 216 twins, Moskowitz et al. (21) showed that after adjusting according to age, height, weight, and gender, the HDL-C level was lower in 8 twin pairs born to the mothers who were smoking during pregnancy, compared to 33 twin pairs born to nonsmoking mothers $(44.6 \pm 2.2$ and $50.2 \pm 1.1 \mathrm{mg} / \mathrm{dL} ; \mathrm{P}<0.05)$. Likewise, in the present study, the HDL-C level was statistically lower in the newborns of smoking mothers, which showed a negative correlation with pack-year and CAIMT.

In a study conducted by Geerts et al. (22), including 456 mothers, systolic and diastolic blood pressures were compared between the neonates born to smoking and nonsmoking mothers. Out of 456 mothers, 363 cases (79\%) did not expose to smoking, 63 cases (13\%) did not smoke but were exposed to tobacco smoke during pregnancy, and 30 cases (6.6\%) smoked during gestation. In conclusion, considering the weight, age, gender, and nutritional status of newborns and age of the mother, systolic blood pressure was observed higher by $5.4 \mathrm{mmHg}(\mathrm{P}=0.01)$ in the neonates of smoking mothers at the age of 2 months; however, no correlation was noticed between diastolic blood pressure and smoking. In a similarly designed study, the blood pressure of newborns was measured at the third and fourth days of life, and only diastolic blood pressure was observed to be increased by $1.7 \mathrm{mmHg}$ in the newborns of smoking mothers (23). The present study compared blood pressure values after delivery between the newborns exposed to gestational smoking and those born to nonsmoking mothers and demonstrated no significant difference in blood pressure levels between the two groups.

Despite the obtained findings, this study had some limitations. First, the sample size of the study was small. The results of the present study should be confirmed with larger series. The second limitation was the short duration of follow-up. The newborns were evaluated within the first month after delivery. Further studies with a longer duration of follow-up are required to investigate whether these neonates' CAIMT and blood lipid levels are influenced. As the third limitation, patients' smoking status was searched verbally, which could involve recall bias risk. Serum cotinine level measurement, a byproduct of nicotine, has previously been shown to accurately determine the quantity of smoking exposure.

\subsection{Conclusion}

No significant differences were observed in heart rate, CAIMT, and TG, TC, and LDL-C levels in the neonates born to smoking mothers, compared to those of the neonates born to nonsmoking mothers; however, a statistically significant decline was noticed in the levels of HDL-C in the study group. Atherosclerosis is a disease in which numerous factors play a role in the formation beginning in the fe- 
tal period and emerging with clinical findings in advanced age; therefore, it is required to perform further studies with longer follow-up and larger sample size to confirm the present study findings.

\section{Footnotes}

Authors' Contribution: Conception of the idea, TM; Design, TM and HT; Study execution, TM, HT, and OD; Provision of study materials, TM, HT, and OD; Manuscript writing, all authors; Statistical analysis, VT and TM; Final approval, all authors.

Conflict of Interests: The authors declare that there is no conflict of interest.

Data Reproducibility: The corresponding author will be responsible for data reproducibility.

Ethical Approval: This study was approved by Dr. Behcet Uz Children's Training and Research hospital (no.: 12/12/2013104).

Funding/Support: There was no funding for this study. Informed Consent: All patients signed the informed consent form.

\section{References}

1. West R. Tobacco smoking: Health impact, prevalence, correlates and interventions. Psychol Health. 2017;32(8):1018-36. doi: 10.1080/08870446.2017.1325890. [PubMed: 28553727]. [PubMed Central: PMC5490618].

2. Office of the Surgeon General(US); Office on Smoking and Health(US). The Health Consequences of Smoking: A Report of the Surgeon General. Atlanta, USA: Centers for Disease Control and Prevention (US); 2004

3. Murray CJ, Lopez AD. Mortality by cause for eight regions of the world: Global Burden of Disease Study. Lancet. 1997;349(9061):1269-76. doi: 10.1016/S0140-6736(96)07493-4. [PubMed: 9142060].

4. Anagnostopoulos C, Henein MY, Underwood SR. Non-invasive investigations. Br Med Bull. 2001;59:29-44. doi: 10.1093/bmb/59.1.29. [PubMed: 11756202].

5. Jarvisalo MJ, Jartti L, Nanto-Salonen K, Irjala K, Ronnemaa T, Hartiala JJ, et al. Increased aortic intima-media thickness: a marker of preclinical atherosclerosis in high-risk children. Circulation. 2001;104(24):29437. doi: 10.1161/hc4901.100522. [PubMed: 11739310].

6. Schwartz SM, Heimark RL, Majesky MW. Developmental mechanisms underlying pathology of arteries. Physiol Rev.1990;70(4):1177-209. doi: 10.1152/physrev.1990.70.4.1177. [PubMed: 2217558].

7. Napoli C, Glass CK, Witztum JL, Deutsch R, D’Armiento FP, Palinski $W$. Influence of maternal hypercholesterolaemia during pregnancy on progression of early atherosclerotic lesions in childhood: Fate of Early Lesions in Children (FELIC) study. Lancet.1999;354(9186):1234-41. doi:10.1016/S0140-6736(99)02131-5. [PubMed: 10520631].

8. Barr DA. The Childhood Roots of Cardiovascular Disease Disparities. Mayo Clin Proc. 2017;92(9):1415-21. doi: 10.1016/j.mayocp.2017.06.013. [PubMed: 28870356].

9. Tamminen M, Mottino G, Qiao JH, Breslow JL, Frank JS. Ultrastructure of early lipid accumulation in ApoE-deficient mice. Arterioscler Thromb Vasc Biol. 1999;19(4):847-53. doi: 10.1161/01.atv.19.4.847. [PubMed: 10195908].
10. Stary HC, Blankenhorn DH, Chandler AB, Glagov S, Insull W, Richardson $\mathrm{M}$, et al. A definition of the intima of human arteries and of its atherosclerosis-prone regions. A report from the Committee on Vascular Lesions of the Council on Arteriosclerosis, American Heart Association. Circulation. 1992;85(1):391-405. doi: 10.1161/01.cir.85.1.391. [PubMed: 1728483].

11. Gunes T, Akin MA, Canoz O, Coban D, Ozcan B, Kose M, et al. Aortic intima-media thickness in nicotine-exposed rat pups during gestation and lactation period. Eur J Pediatr. 2011;170(10):1257-62. doi: 10.1007/s00431-011-1432-7. [PubMed: 21360026].

12. Geerts CC, Bots ML, Grobbee DE, Uiterwaal CS. Parental smoking and vascular damage in young adult offspring: is early life exposure critical? The atherosclerosis risk in young adults study. ArteriosclerThromb Vasc Biol. 2008;28(12):2296-302. doi: 10.1161/ATVBAHA.108.173229. [PubMed: 19020316].

13. Geerts CC, Bots ML, van der Ent CK, Grobbee DE, Uiterwaal CS. Parental smoking and vascular damage in their 5-year-old children. Pediatrics. 2012;129(1):45-54. doi: 10.1542/peds.2011-0249. [PubMed: 22201150].

14. Wiegman A, de Groot E, Hutten BA, Rodenburg J, Gort J, Bakker HD, et al. Arterial intima-media thickness in children heterozygous for familial hypercholesterolaemia. Lancet. 2004;363(9406):369-70. doi: 10.1016/S0140-6736(04)15467-6. [PubMed: 15070569].

15. Atabek ME, Kurtoglu S, Demir F, Baykara M. Relation of serum leptin and insulin-like growth factor-1 levels to intima-media thickness and functions of common carotid artery in children and adolescents with type 1 diabetes. Acta Paediatr. 2004;93(8):1052-7. doi:10.1111/j.16512227.2004.tb02717.x. [PubMed: 15456195].

16. He BM, Zhao SP, Peng ZY. Effects of cigarette smoking on HDL quantity and function: implications for atherosclerosis. J Cell Biochem. 2013;114(11):2431-6. doi: 10.1002/jcb.24581. [PubMed: 23852759].

17. West HW, Juonala M, Gall SL, Kahonen M, Laitinen T, Taittonen L, et al. Exposure to parental smoking in childhood is associated with increased risk of carotid atherosclerotic plaque in adulthood: the Cardiovascular Risk in Young Finns Study. Circulation. 2015;131(14):123946. doi: 10.1161/CIRCULATIONAHA.114.013485. [PubMed: 25802269].

18. Juonala M, Magnussen CG, Raitakari OT. Parental smoking produces long-term damage to vascular function in their children. Curr Opin Cardiol. 2013;28(5):569-74. doi: 10.1097/HCO.ob013e3283642882. [PubMed: 23928922].

19. Ayer JG, Belousova E, Harmer JA, David C, Marks GB, Celermajer DS. Maternal cigarette smoking is associated with reduced highdensity lipoprotein cholesterol in healthy 8-year-old children. Eur Heart J. 2011;32(19):2446-53. doi: 10.1093/eurheartj/ehr174. [PubMed: 21693475].

20. Gordon DJ, Probstfield JL, Garrison RJ, Neaton JD, Castelli WP, Knoke JD, et al. High-density lipoprotein cholesterol and cardiovascular disease. Four prospective American studies. Circulation. 1989;79(1):8-15. doi:10.1161/01.cir.79.1.8. [PubMed: 2642759].

21. Moskowitz WB, Mosteller M, Schieken RM, Bossano R, Hewitt JK, Bodurtha JN, et al. Lipoprotein and oxygen transport alterations in passive smoking preadolescent children. The MCV Twin Study. Circulation. 1990;81(2):586-92. doi: 10.1161/01.cir.81.2.586. [PubMed: 2297864].

22. Geerts CC, Grobbee DE, van der Ent CK, de Jong BM, van der Zalm MM, van Putte-Katier N, et al. Tobacco smoke exposure of preg nant mothers and blood pressure in their newborns: results from the wheezing illnesses study Leidsche Rijn birth cohort. Hypertension. 2007;50(3):572-8. doi: 10.1161/HYPERTENSIONAHA.107.091462. [PubMed: 17664395].

23. O'Sullivan MJ, Kearney PJ, Crowley MJ. The influence of some perinatal variables on neonatal blood pressure. Acta Paediatr. 1996;85(7):84953. doi: 10.1111/j.1651-2227.1996.tb14166.x. [PubMed: 8819553]. 